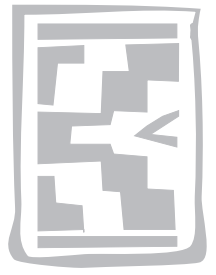

\title{
Macroscopic features of the venous drainage of the reproductive system of the male ostrich (Struthio camelus)
}

\author{
M.Z.J. ELIAS ${ }^{1}$, T.A. AIRE and J.T. SOLEY* \\ Department of Anatomy and Physiology, Faculty of Veterinary Science, University of Pretoria \\ Onderstepoort, 0110 South Africa
}

\begin{abstract}
ELIAS, M.Z.J., AIRE, T.A. \& SOLEY, J.T. 2008. Macroscopic features of the venous drainage of the reproductive system of the male ostrich (Struthio camelus). Onderstepoort Journal of Veterinary Research, 75:289-298

The macroscopic features of the venous drainage of the reproductive system of the male ostrich were studied in six pre-pubertal and three sexually mature and active birds. Each testis was drained by one to four testicular veins. The right testicular veins drained the right testis and epididymis and its appendix to the caudal vena cava and to the right common iliac vein, whereas the left testicular veins drained the left testis and epididymis and its appendix exclusively to the left common iliac vein. A number of variations in the drainage pattern based on the point of entry and number of testicular veins were observed. The cranial aspect of the testis was also linked to the caudal vena cava or common iliac vein via the adrenal veins. The cranial, middle and caudal segments of the ductus deferens (and ureter) were drained by the cranial, middle and caudal ureterodeferential veins respectively, to the caudal testicular veins, the caudal renal veins and pudendal/caudal part of the internal iliac veins. In some specimens, the caudal ureterodeferential veins also drained into the caudal mesenteric vein. The surface of the phallus was drained by tributaries of the pudendal vein. The basic pattern of venous drainage of the reproductive organs of the male ostrich was generally similar to that described for the domestic fowl. However, important differences, including the partial fusion of the caudal renal veins, drainage of the cranial aspect of the testes via the adrenal veins, drainage of the caudal ureterodeferential veins into the caudal mesenteric vein and the presence of veins draining the surface of the phallus, were observed. Although significant, these differences may simply reflect variations in the normal pattern of venous drainage of the reproductive tract of birds which could be verified by studying more specimens and more species.
\end{abstract}

Keywords: Macroscopic features, male reproductive system, ostrich, Struthio camelus, veins

\section{INTRODUCTION}

The vascular system of the male reproductive tract in birds has, in general, been poorly studied. The only comprehensive report of both the arterial supply and venous drainage is that of Nishida (1964) in

* Author to whom correspondence is to be directed. E-mail: john.soley@up.ac.za

1 Present address: Veterinary Faculty, Department of Preclinics, Eduardo Mondlane University, Maputo, Mozambique

Accepted for publication 10 September 2008-Editor the domestic fowl. A general description of the arterial supply to the male reproductive organs of the pigeon has also been provided (Bhaduri, Biswas \& Das 1957) and a more recent study (Elias, Aire \& Soley 2007) has described the macroscopic features and variations in the arterial supply to the reproductive tract of the male ostrich. The venous system has received even less attention, with most of the information being supplied by Nishida (1964) and some incidental data being provided from a study on the renal portal and venous systems of the fowl kidney by Kurihara \& Yasuda (1975). Descrip- 
tions of the venous system involving the male reproductive tract of birds presented in textbooks [e.g. Baumel (1975), Lake (1981) and Baumel (1993)] simply reflect the work of Nishida (1964) and Kurihara \& Yasuda (1975). The only reference to drainage of the reproductive organs in the male ostrich is by Bezuidenhout (1999) who notes that "as the caudal vena cava passes cranially and ventrally it receives veins from the gonads, adrenals and surrounding tissues".

In view of the lack of comparative data on the vascularization of the male reproductive tract of birds, and considering the need for a better understanding of the reproductive biology of the ostrich as a farmed animal, this paper presents a description of the gross pattern of venous drainage in the male ostrich. Variations in the basic pattern are also described. The terminology used is that of Nomina Anatomica Avium (Baumel, King, Breazile, Evans \& Berge 1993).

\section{MATERIALS AND METHODS}

The torsos of nine male ostriches with viscera intact, but which had been skinned and from which the limbs had been removed, were obtained from the Oryx Abattoir in Krugersdorp, Gauteng Province and from the Klein Karoo Abattoir in Oudtshoorn, Western Cape Province, South Africa. The specimens comprised six semi-adult birds (12-14 months old) and three sexually mature and active birds. The torsos were prepared as follows for latex injection and the formation of resin casts, respectively.

The venous system of five of the birds (four semiadults and one sexually mature bird) was flushed free of blood by rinsing with physiological saline injected through the caudal vena cava $(5-10 \mathrm{~cm}$ above the vessel's origin between the cranial poles of the testes), after which blue "Latex", (Revertex Chemicals Company $\AA^{\circledR}$, Pretoria) was subsequently injected into the veins via the same route using a 50 $\mathrm{m} \ell$ syringe. The torsos were trimmed of excess tissue and immersion fixed in a $10 \%$ formalin bath for a number of days. The fixed specimens were rinsed in running water for 2 days after which they were carefully dissected to expose the latex-filled veins. The pattern of venous drainage was described and digitally recorded with a Nikon 4500 Coolpix digital camera.

For the preparation of resin casts of the veins, four torsos (two semi-adults and two sexually active birds) were injected with a coloured resin (Pigment Preparation Pty. Ltd., Pretoria) via the caudal vena cava using the same technique employed for the latex injections. Each specimen was subsequently kept for a number of days in a cold room before tissue maceration in a bath containing a $20-30 \%$ sodium hydroxide solution. The corrosion casts obtained were carefully washed clean and the pattern of veins described and digitally recorded.

\section{RESULTS}

\section{Venous drainage of the testes}

The testes were drained via testicular veins (venae testiculares) that were variable in number (ranging from one to four for each testis) and point of termination (Fig. 1, 2A-C and 3). These veins were observed to arise from a well-developed venous network located in the testicular capsule (Fig. 3). Based on the relationship of the testicular veins to the caudal vena cava and the common iliac veins, the following variations were observed:

Type $A$ In this variation, the testicular veins draining the right testis, the epididymis and its appendix, and the cranial aspect of the ductus deferens and ureter, joined both the caudal vena cava (just cranial to its origin) and the right common iliac vein. The vessels draining the left testis and associated structures emptied exclusively into the left common iliac vein, caudal to the confluence of the two common iliac veins (Fig. 1, $2 \mathrm{~B}$ and 3 ) This was the most common pattern noted and occurred in five $(55.5 \%)$ of the specimens examined.

Type $B$ This variation was observed in four (44.5\%) of the specimens and was characterized by the right testicular veins draining only into the caudal vena cava, while the left testicular veins again emptied into the left common iliac vein (Fig. $2 A$ and $C$ ).

As noted above, the testes displayed a well-developed venous network situated in the testicular capsule, particularly in the sexually mature birds, and from which the testicular veins emanated. Due to the complexity of this network and the formation of numerous tributaries, it was difficult in some specimens to accurately determine the exact number of testicular veins present. However, based on obvious connections between the testicular veins and the caudal vena cava and common iliac veins, four basic numerical patterns were observed.

Type I In this variation at least four testicular veins were observed to drain the right testis while a similar number drained the left testis (Fig. 


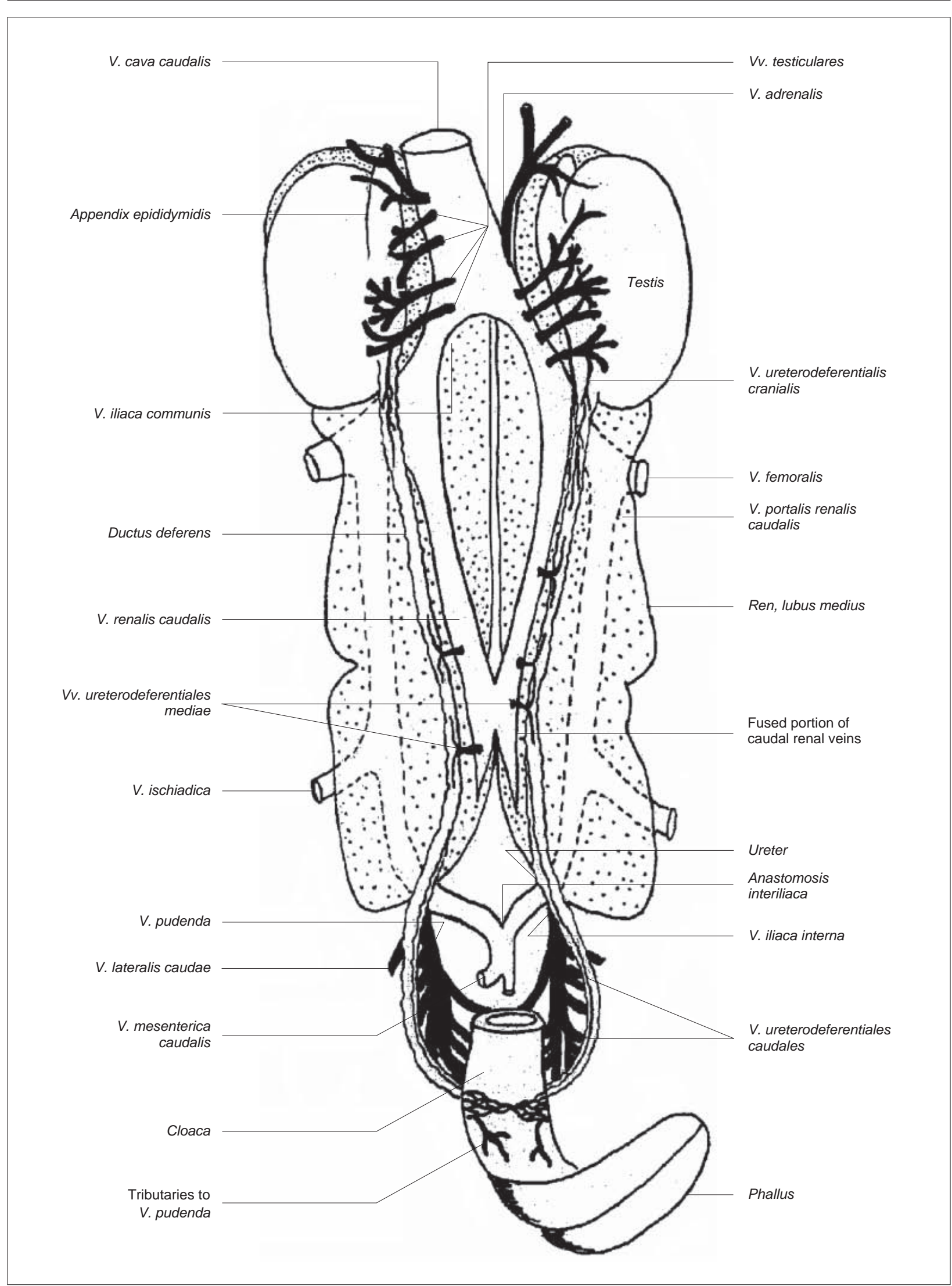

FIG. 1 A diagramatic sketch showing, in ventral view, the main veins draining the reproductive tract of the male ostrich. The testes are shown reflected laterally to illustrate the testicular veins and associated vessels 

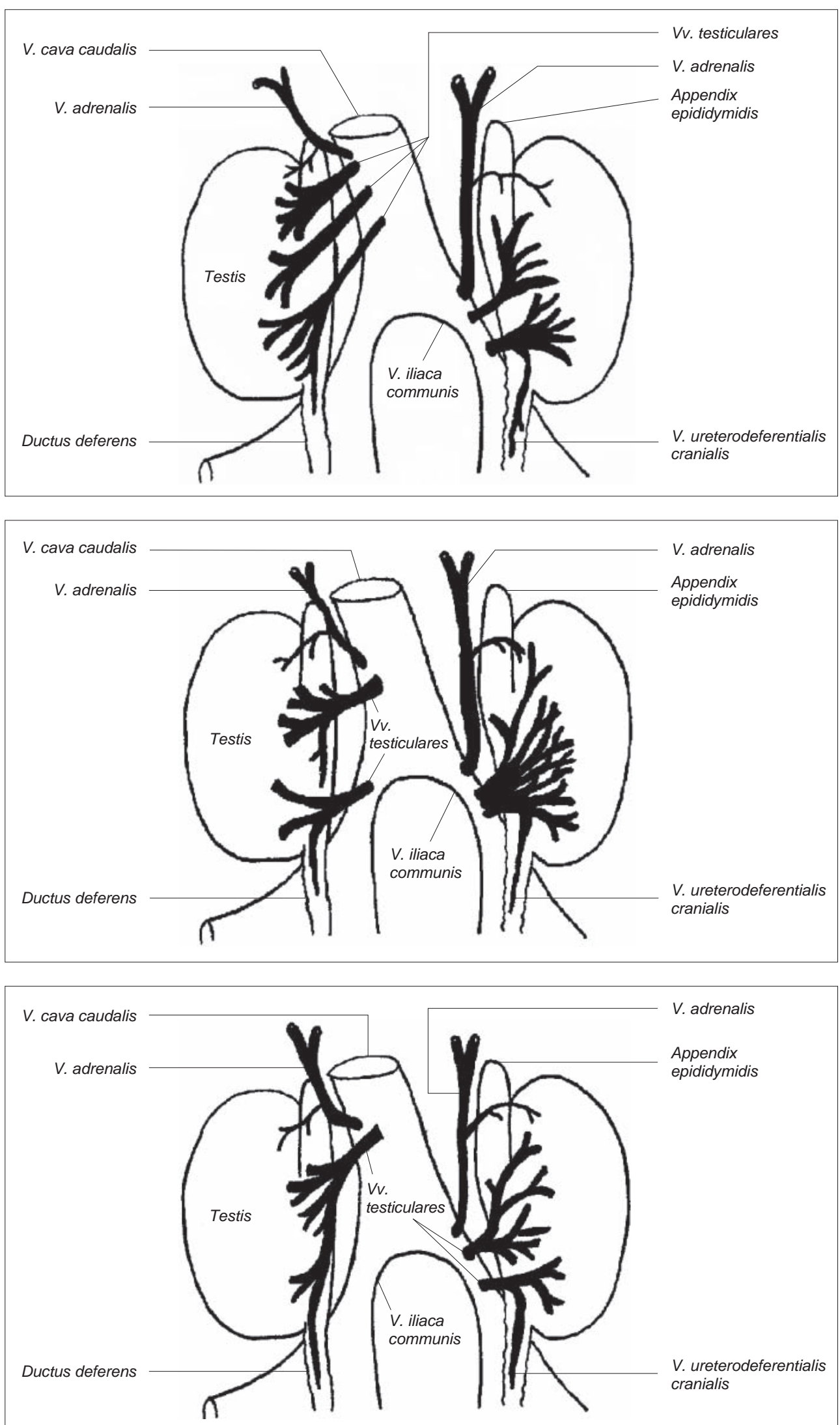

FIG. 2A-C Diagramatic sketches showing, in ventral view, the main variations of the testicular veins in respect of their number and location 
1 and 3). This was the most common pattern noted and occurred in three (33.4\%) of the specimens examined.

Type /I In this instance three testicular veins (essentially cranial, middle and caudal vessels) drained the right testis and two testicular veins (cranial and caudal) the left testis (Fig. 2A). This variation occurred in two $(22.2 \%)$ of the specimens.

Type III This type was characterized by the presence of two testicular veins draining the right testis and a single, large testicular vein draining the left testis. The latter was formed by a large number of branched tributaries (Fig. 2B). This variation was present in two $(22.2 \%)$ of the specimens examined.
Type IV This variation was also observed in two $(22.2 \%)$ of the specimens and consisted of a single testicular vein draining the right testis and two veins draining the left testis (Fig. 2C). Each of these vessels was composed of numerous tributaries.

It was observed in all specimens that a small vessel (effectively an additional testicular vein?) emanated from the venous network at the cranial aspect of each gonad and emptied into the adrenal vein. (Fig. $1,2 \mathrm{~A}-\mathrm{C}, 3$ and 4$)$. In the ostrich this vessel was prominent and well-developed on the left side of the body where it drained into the left common iliac vein. The adrenal vein was smaller on the right side where it emptied into the caudal vena cava. In addition to draining the cranial aspect of the testis, the adrenal vein drained part of the appendix epididymidis, the

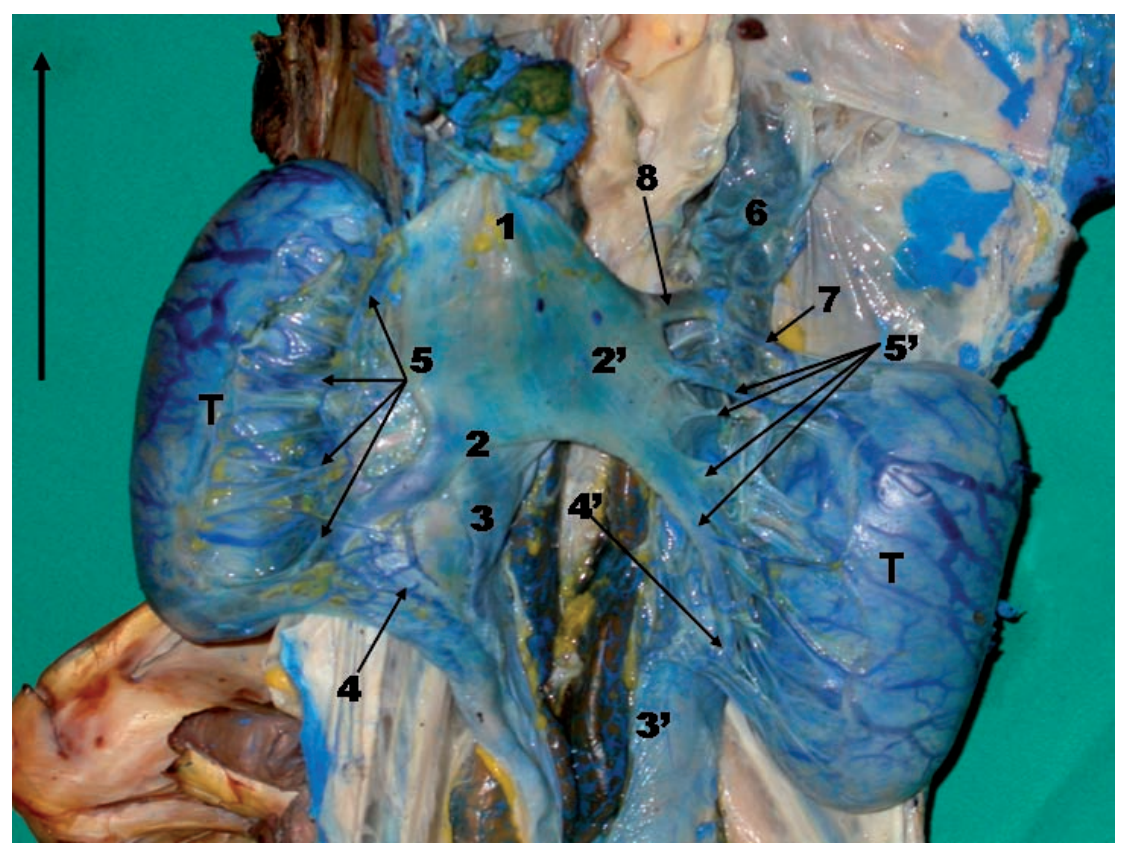

FIG. 3 Ventral view of the reproductive tract of the ostrich illustrating the testes ( $T$ ) and associated veins. The testes have been reflected laterally to expose more clearly the relevant veins. Note the extensive venous network within the testicular capsule. $V$. cava caudalis (1), Vv. iliacae communes dextra et sinistra (2, 2'), $V v$. renales caudales dextra et sinistra $\left(3,3^{\prime}\right), V v$. ureterodeferentiales craniales dextra et sinistra (4, 4'), Vv. testiculares dextra et sinistra $(5,5)$, Appendix epididymidis (6), Branch draining the cranial pole of the testis to the adrenal vein (7). $V$. adrenalis sinistra (8). Arrow at top left indicates caudo-cranial direction. Latex injection

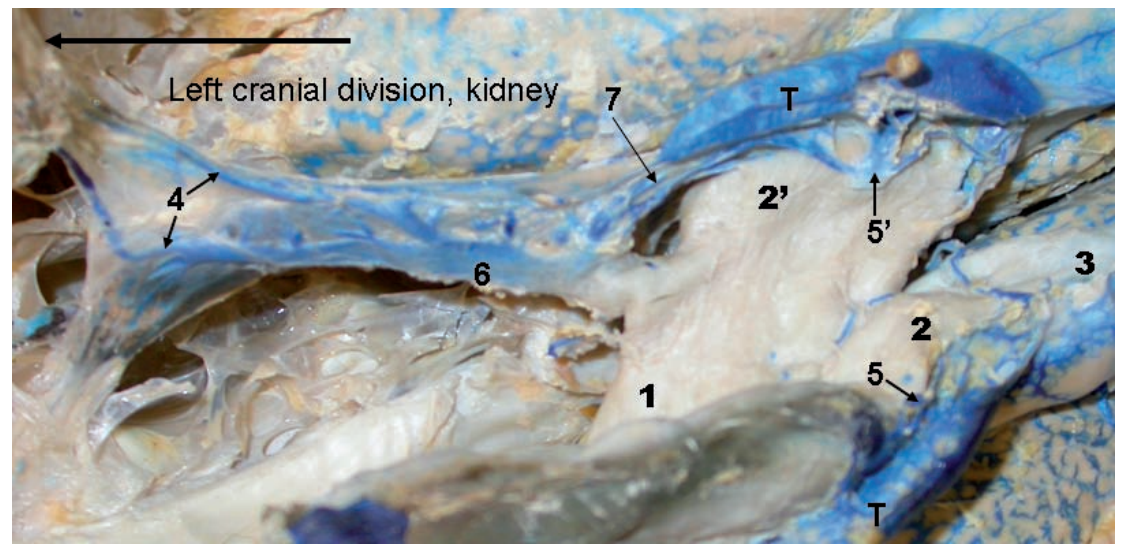

FIG. 4 Ventral view of the thoraco-abdominal region of a pre-pubertal bird illustrating the testes (T) and associated veins. $V$. cava caudalis (1), Vv. iliacae communes dextra et sinistra $(2,2), V$. renalis caudalis dextra (3), $V v$. testiculares dextra et sinistra $(5,5), V$. adrenalis sinistra (6). Note the branches from the latero-dorsal body wall (4) draining into the adrenal vein (6) as well as a testicular vein (7) that drains the left testis into the left common iliac vein via the adrenal vein. Arrow top left indicates caudo-cranial direction. Latex injection 

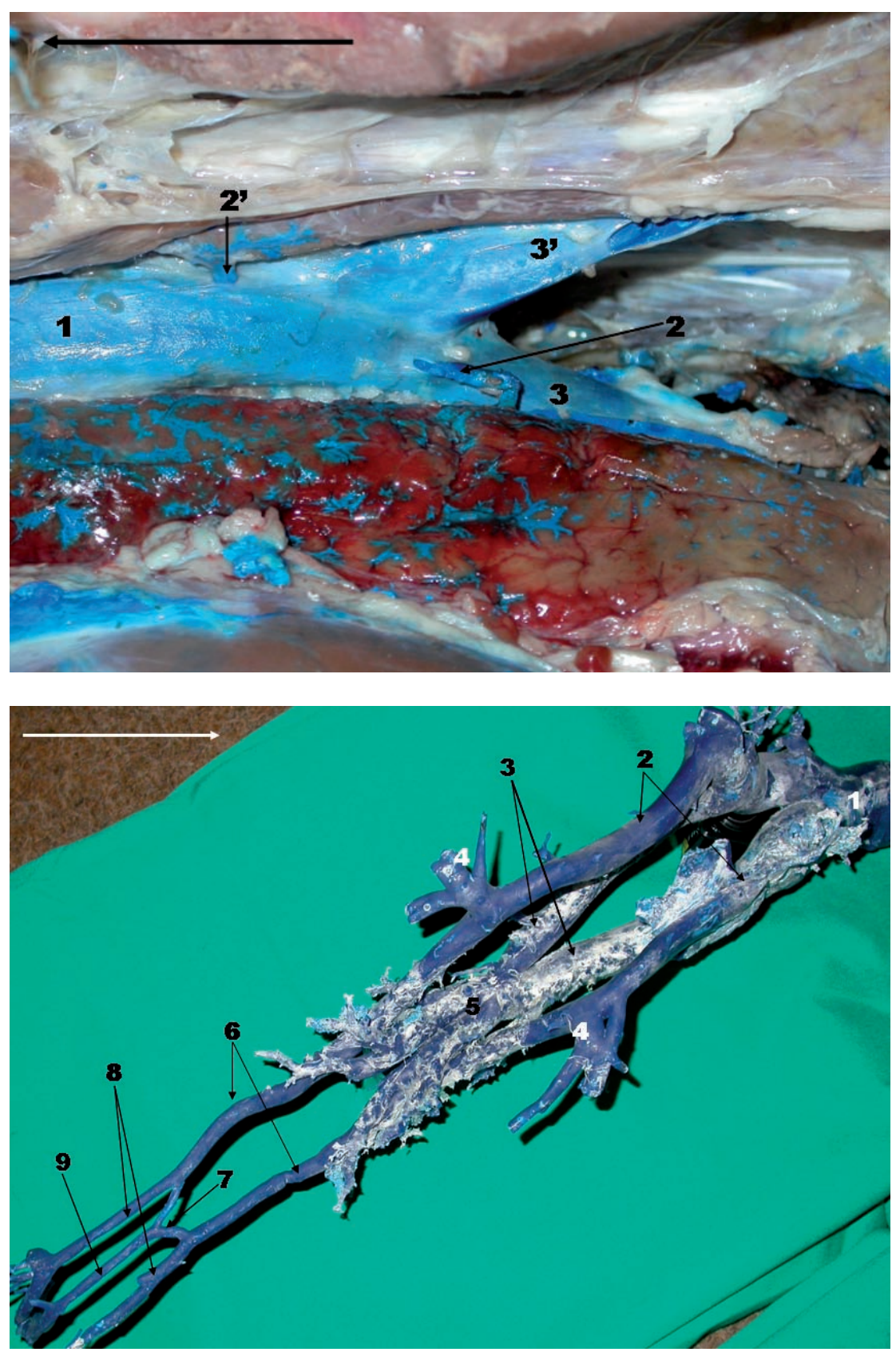

FIG. 5 A ventral view of the middle segment of the reproductive tract showing the region of fusion between the left and right caudal renal veins (1), Vv. ureterodeferentiales mediae dextra et sinistra $(2,2 '), V v$. renales caudales dextra et sinistra $\left(3,3^{\prime}\right)$. Arrow top left indicates caudo-cranial direction. Latex injection
FIG. 6 A corrosion cast (dorsal view) showing the main components of the venous system involved in drainage of the male reproductive tract: $V$. cava caudalis (1), Vv. iliacae communes (2), $V v$. renales caudales (3). $V v$. ischiadicae (4), fused portion of caudal renal veins (5), $V v$. portales renales caudales (6), anastomosis interiliaca (7), $V v$. iliacae internae (8) and V. caudae medianae (9). Arrow top left indicates caudo-cranial direction. Latex injection adrenal gland and the cranio-lateral body wall of the thoraco-abdominal region. Very fine branches of the adrenal vein also drained the cranial division of the kidney.

The position and course of the caudal vena cava of the ostrich were similar to that described for the fowl (Gallus domesticus) (Nishida 1964). It was formed by the confluence of the right and left common iliac veins in the vicinity of the cranial poles of the testes, the adrenal glands and cranial divisions of the kidneys, where it lay almost directly below the aorta. In the material studied, the caudal vena cava varied between $2-4 \mathrm{~cm}$ in width, and $20-28 \mathrm{~cm}$ in length. It lay slightly to the right of the median plane and coursed obliquely cranioventrally (Fig. 1 and 3) towards the right atrium of the heart.

\section{Drainage of the ductus deferens}

The cranial aspect of each deferent duct was drained by the most caudal testicular vein through the cranial ureterodeferential vein (vena ureterodeferentialis cranialis) (Fig. 1, 2A-C and 3). 
FIG. 7 Ventro-lateral view of the pelvic region displaying the $V v$. iliacae internae dextra et sinistra $\left(1,1^{\prime}\right), V v$. pudendae dextra et sinistra $(2,2)$, $V$. mediana caudae (3), Vv. ureterodeferentiales caudae (4), Ductus deferentes et ureteres dextrae et sinistrae $\left(5,5^{\prime}\right), V$. mesenterica caudalis (6). Note the caudal ureterodeferential vein (4-single white arrow) draining the ductus deferens (5) to the caudal mesenteric vein (6), Arrow top left indicates caudocranial direction. Latex injection

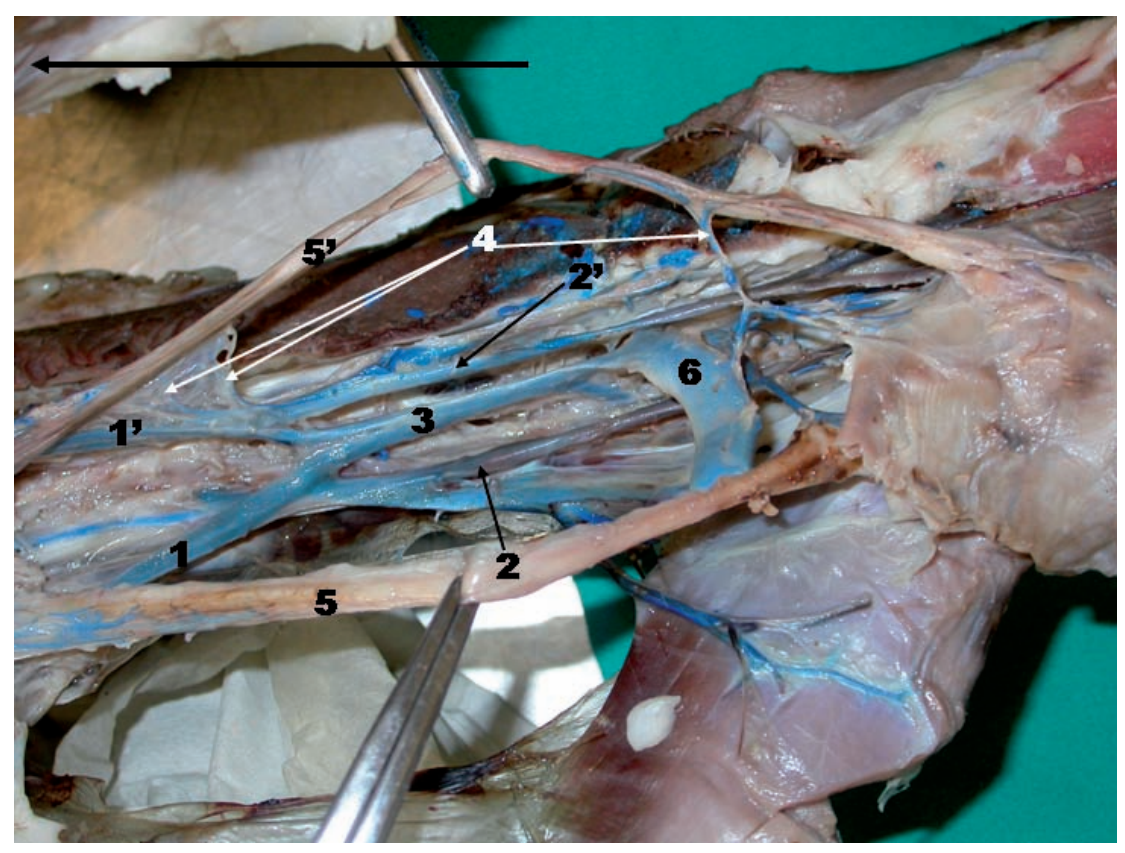

FIG. 8 Ventro-lateral view of the pelvic region showing the $V$. iliaca interna sinistra (1), V. pudenda sinistra (2), V. caudae medianae (3), V. ureterodeferentialis caudalis (4), Ductus deferentes et ureteres sinistrae (5). In this view the exact positioning of the veins in the pelvic region has been obscured to illustrate the anastomosis between the $V$. mesenterica caudalis (7) and the left internal iliac vein (1) via a large unnamed vein (6). Arrow top left indicates caudo-cranial direction. Latex injection

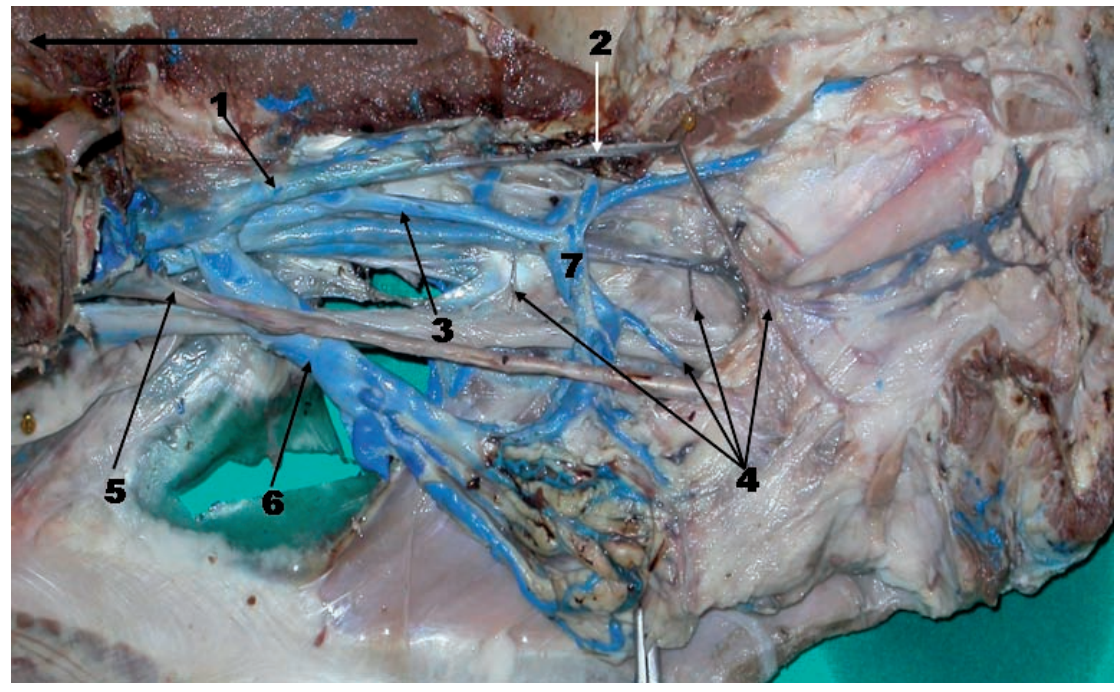

The middle portions of the deferent duct and ureter were drained by the middle ureterodeferential veins (venae ureterodeferentiales mediae). These vessels were variable in number, size and point of entry along the caudal renal veins into which they emptied. The caudal renal veins also drained the caudal part of the cranial division and all of the middle and caudal divisions of the kidney as well as the ureter in those regions. The caudal renal veins were observed to fuse with each other at a level between the caudal and middle renal lobes (Fig. 1, 5 and 6) to form a single vessel approximately $3-5 \mathrm{~cm}$ long, before again dividing cranially into two separate vessels. In all specimens studied, the middle ureterodeferential veins emptied into both the fused and separated parts of the caudal renal veins. The cranial continuation of the caudal renal veins drained ventro-caudally into the common iliac veins (Fig. 1 and 3), while the femoral veins (vena femoralis) entered the common iliac veins dorso-laterally. Each common iliac vein (vena illiaca communis) emptied into the caudal vena cava in the vicinity of the cranial aspect of the testes.

The caudal part of the deferent duct and the cloaca were drained by the caudal ureterodeferential veins (venae ureterodeferentiales caudales) to the pudendal veins and to the caudal portion of the internal iliac veins. Each pudendal vein (vena pudenda), after receiving the caudal lateral vein (from the wall 


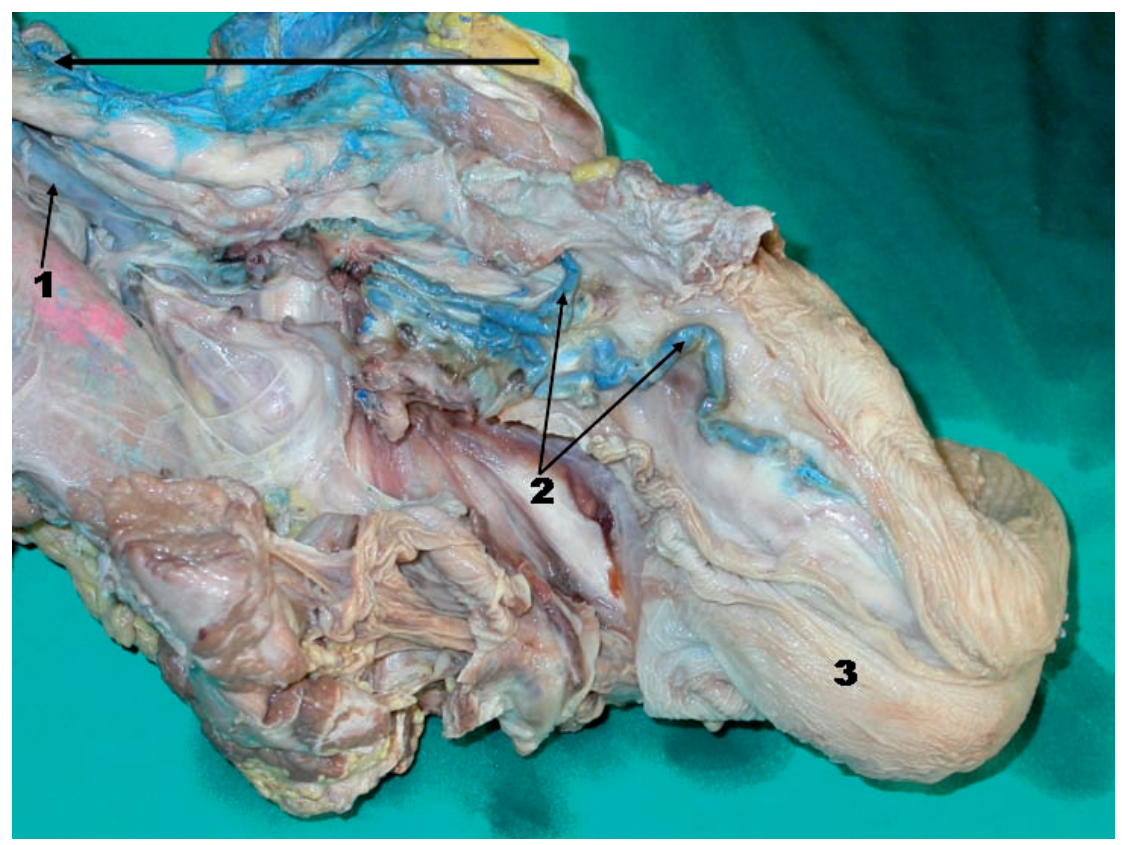

FIG. 9 Ventro-lateral view of the phallus showing the $V$. pudenda dextra (1) receiving large, superficial tributaries (2) from the root and body of the phallus (3). Arrow top left indicates caudo-cranial direction. Latex injection

of the pelvic region) formed the internal iliac vein (Fig. 7 and 8). The two internal iliac veins proceeded cranially and were connected by a transverse vessel, the interiliac anastomosis, $2-5 \mathrm{~cm}$ caudal to the caudal pole of the kidney. The anastomosis was linked caudally to the caudal median vein (Fig. 6 and 7$)$. In three specimens (33.3\%), tributaries from the caudal deferent duct, together with branches from the rectum and cloaca, were observed to drain into the caudal mesenteric vein (vena mesenterica caudalis) in addition to the branches draining into the pudendal vein. The caudal mesenteric vein emptied into the caudal median vein (Fig. 7). In one of these specimens the caudal mesenteric vein, in addition to its connection to the caudal median vein, was linked to the left internal iliac vein by a large unnamed vessel draining the wall of the rectum (Fig. 8).

\section{Drainage of the phallus}

A number of superficial tributaries displaying no particular pattern drained the mucosa, but not the substance of the phallus, (Fig. 1 and 9) to the pudendal vein. These vessels were relatively large (Fig. 9). A venous network of fine vessels was situated at the root of the phallus which also drained into the pudendal vein (Fig. 1).

\section{DISCUSSION}

The gross pattern of venous drainage of the male reproductive tract in the ostrich is basically similar to that described for the fowl (Nishida 1964). However, certain noteworthy variations were observed in the material studied which may reflect unreported differences between avian species.

In both the ostrich and fowl (Nishida 1964) the testicular veins arise from a well-developed network located in the testicular capsule. In the fowl both sets (left and right) of testicular veins are reported to empty into the corresponding common iliac vein and the caudal vena cava as illustrated in the sketch by Nishida (1964). In other studies on the fowl, however, the testicular veins are shown to empty only into the caudal vena cava (Nickel, Schummer \& Seiferle 1977). A similar situation is also illustrated for the veins draining the single ovary of Gallus (Baumel 1993). In five of the ostriches studied, the drainage pattern of the right testis resembled that described by Nishida (1964) (testicular veins emptied into the right common iliac vein and the caudal vena cava) whereas the testicular veins from the left testis emptied exclusively into the left common iliac vein. In four birds, however, the testicular veins emanating from the right testis drained only into the caudal vena cava, with those from the left testis again emptying into the left common iliac vein.

In the ostrich, therefore, the route of drainage of the right testicular veins reflects both patterns reported in the fowl. However, the exclusive drainage of the left testicular veins into the corresponding common iliac vein in all the ostrich specimens examined appears to be a unique feature and contrasts sharply with the observation that in the ostrich the veins from the gonads empty into the caudal vena cava 
(Bezuidenhout 1999). The slightly more cranial positioning of the right testis reported in the ostrich (Soley 1992; Soley \& Groenewald 1999) may provide an explanation for that drainage into both the right common iliac vein and the caudal vena cava or only into the caudal vena cava, and to the exclusive drainage of the more caudally positioned left testis into the left common iliac vein.

Little information is available in the literature regarding the numerical patterns of the testicular veins. The illustration of Nishida (1964) shows one large vein draining the right testis and three vessels draining the left testis, similar to the Type IV variation reported in the present study. As the authors did not have a full English translation of the text available, it is possible that a range of variations were described by Nishida (1964). The illustration by Nickel et al. (1977) demonstrates at least three veins draining both the left and right testes respectively which corresponds closely with the most common variation (Type I) seen in the ostrich involving four testicular veins draining each testis. These observations would suggest that a range of numerical variations is typical for the testicular veins of birds.

An interesting observation in the ostrich was the presence of a small vessel emanating from the venous network at the cranial aspect of each gonad and which drained into the adrenal vein. This drainage route for the testes has not been reported in the fowl although Baumel (1993) illustrates some $V v$. ovaricae reaching the caudal vena cava via the adrenal vein. In the ostrich, the adrenal vein on the left side of the body drained into the left common iliac vein whereas that on the right side emptied into the caudal vena cava. In the fowl both the left and right adrenal veins reportedly drain into the caudal vena cava (Goodchild 1969; Baumel 1993). Again, the unequal positioning of the ostrich testes may account for this phenomenon.

In the ostrich, drainage of the cranial and middle segments of the ductus deference parallels that described in the fowl (Nishida 1964). The cranial aspect of the ductus deferens and ureter are drained by the cranial ureterodeferential veins to the most caudal testicular veins and from there to the common iliac veins or caudal vena cava. However, it is not clear whether the cranial ureterodeferential veins in the fowl ( $V v$. ureto-deferentiales anteriores - Nishida 1964) reach the common iliac veins independently or via the caudal testicular veins.

In both the ostrich and fowl, middle ureterodeferential veins ( $V v$. ureto-deferentiales mediae - Nishida
1964) drain the middle segments of the ductus deferens and ureter to the caudal renal veins ( $V$. renalis efferens - Nishida 1964). A marked difference in the ostrich is that some of the middle ureterodeferential veins enter the fused portion of the left and right caudal renal veins, a situation lacking in the fowl as fusion of the caudal renal veins does not occur (Akester 1964; Kurihara \& Yasuda 1975; Baumel 1993). Fusion of the caudal renal veins has only previously been reported in a single 5-day old chicken embryo (Miller 1903). Why this phenomenon should be a consistent feature in the ostrich, or what its functional significance is, remains unknown.

In six of the nine specimens, the caudal ureterodeferential veins in the ostrich were observed to drain into the pudendal vein and the caudal aspect of the internal iliac vein which formed the continuation of the former vessel. In three specimens, however, the caudal ureterodeferential veins were seen to drain into the caudal mesenteric vein in addition to the branches draining into the pudendal vein. In the fowl the caudal ureterodeferential veins ( $V v$. ureto-deferentiales posteriors - Nishida 1964) are shown draining only into the pudendal vein ( $V$. pudenda interna - Nishida 1964). As a caudal mesenteric vein ( $V$. coccygomesenterica - Nickel et al. 1977) has been described in the fowl (Nickel et al. 1977; Baumel 1993) it is possible that in this species branches of the caudal ureterodeferential veins do in fact empty into this vessel but have not yet been described. It was also noted that in the ostrich the caudal mesenteric vein drained into the caudal median vein which in turn was linked to the interiliac anastomosis. In the fowl, both the caudal median vein and the caudal mesenteric vein appear to drain into the interiliac anastomosis (Baumel 1993, page 467), although alternative drainage patterns have also been described (Kurihara \& Yasuda 1975; Baumel 1993).

The large tributaries draining the mucosa of the phallus to the pudendal vein in the ostrich have not been described in the fowl. This omission may be due to the relatively small size of the phallus and the attendant difficulties in revealing the blood vessels in this species.

In conclusion, the pattern of venous drainage of the reproductive organs of the male ostrich follows the basic pattern described in the domestic fowl by Nishida (1964). Although the differences observed between the ostrich and fowl are significant, they may simply reflect variations in the normal pattern of venous drainage of the reproductive tract of birds which could be verified by studying more specimens and more species. 


\section{ACKNOWLEDGEMENTS}

We thank the Swedish International Development Agency, Project UEM INIVEVETER SIDA-SAREC 2001-2003, for funding this study, Mrs W. Oliver for preparing the original art work and Mr L. de Villiers for assistance in obtaining the specimens.

\section{REFERENCES}

AKESTER, A.R. 1964. Radiographic studies of the renal portal system in the domestic fowl (Gallus domesticus). Journal of Anatomy, 98:365-376.

BAUMEL, J.J. 1975. Heart and blood vessels, in The anatomy of domestic animals. Vol. 2, edited by R. Getty. Philadelphia: Saunders Company.

BAUMEL, J.J. 1993. Systema cardiovascular, in Handbook of avian anatomy. Nomina Anatomica Avium, $2^{\text {nd }}$ ed., edited by A.S. King, J.E. Breazile, H.E. Evans \& J.C.V. Berge. Cambridge: Academic Press.

BAUMEL, J.J., KING, A.S., BREAZILE, J.E., EVANS, H.E. \& BERGE, J.C.V. (Eds) 1993. Handbook of avian anatomy. Nomina Anatomica Avium, $2^{\text {nd }}$ ed. Cambridge: Academic Press.

BHADURI, J.L., BISWAS, B. \& DAS, S.K. 1957. The arterial system of the domestic pigeon (Columba livia Gmelin). Anatomischer Anzeiger, 104:1-14.

BEZUIDENHOUT, A.J. 1999. Anatomy, in The ostrich, biology, production and health, edited by D.C. Deeming. Cambridge: $\mathrm{CABI}$ Publishing.
ELIAS, M.Z.J., AIRE, T.A. \& SOLEY, J.T. 2007. Macroscopic features of the arterial supply to the reproductive system of the male ostrich (Struthio camelus). Anatomia, Histologia \& Embryolgia: Journal of Veterinary Medicine Series C, 36: 255-262.

GOODCHILD, W.M. 1969. The venous system of the adrenal glands of Gallus domesticus. British Poultry Science, 10:183185.

KURIHARA, S. \& YASUDA, M. 1975. Morphological study of the kidney in the fowl. II. Renal portal and venous systems. Japanese Journal of Veterinary Science, 37:363-377.

LAKE, P.E. 1981. Male genital organs, in Form and function in birds, edited by A.S. King \& J. McLelland. London: Academic Press.

MILLER, A.M. 1903. The development of postcaval vein in birds. American Journal of Anatomy, 2:283-298.

NICKEL, R., SCHUMMER, A. \& SEIFERLE, E. 1977. Circulatory system, in Anatomy of the Domestic Birds. Berlin: Verlag Parey.

NISHIDA, T. 1964. Comparative and topographical anatomy of the fowl. XLII. Blood vascular system of the male reproductive organs. Japanese Journal of Veterinary Science, 26:211221.

SOLEY, J.T. 1992. A histological study of spermatogenesis in the ostrich (Struthio camelus). Ph.D. thesis. University of Pretoria.

SOLEY, J.T. \& GROENEWALD, H.B. 1999. Reproduction, in The ostrich, biology, production and health, edited by D.C. Deeming. London: CABI Publishing. 